\title{
Typical Kawasaki disease
}

\author{
Alessandra Marchesi,, Isabella Tarissi, Giulia Marucci, Alberto Villani \\ From 71st Congress of the Italian Society of Pediatrics. Joint National Meeting SIP, SIMGePeD, Study Group \\ on Pediatric Ultrasound, SUP Study Group on Hypertension \\ Rome, Italy. 4-6 June 2015
}

Kawasaki disease (KD) was first described in Japan in 1967 by Tomisaku Kawasaki [1]. It is an acute, systemic, self-limited vasculitis, whose targets are medium diameter vessels in each organ and apparatus. It is a vasculitis of unknown aetiology, probably multifactorial, that occurs predominantly in infants and young children. The most important complications are coronary arteries aneurysms or ectasia, that develop in 15\% to $25 \%$ of untreated patients, but only in $5 \%$ of patients treated with immunoglobulins within ten days following onset of fever [2,3].

Typical Kawasaki disease is characterized by signs and symptoms which are defined as "diagnostic clinical criteria", and are:

$-\geq 5$ days of fever

- bilateral non-exudative conjunctivitis

- erythema of the lips and oral mucosa

- changes in the extremities (i.e. erythema of the palms and soles or firm, sometimes painful induration of the hands or feet, erythema of the perineal region)

- cutaneous rash

- cervical lymphadenopathy $[3,4]$.

Diagnosis of KD is based on clinical criteria [3,4]: there are neither typical clinical features nor diagnostic tests. An increasing number of children is reported in literature, having coronary artery aneurysms or ectasia, but who do not fulfill all diagnostic criteria. These cases are defined as incomplete $K D$ and atypical $K D$.

Typical KD is diagnosed if:

- fever $\geq 5$ days associated with $\geq 4$ diagnostic criteria, even before performing echocardiography

\footnotetext{
* Correspondence: alessandra.marchesi@opbg.net

Internal Care Medicine Department, Bambino Gesù Children's Hospital, 00165 Roma, Italy
} zero/1.0/) applies to the data made available in this article, unless otherwise stated. teria and possible coronary arteries lesions

- fever at fourth day with $\geq 4$ diagnostic criteria and possible coronary arteries lesions.

Finally, other clinical findings may be present in KD:

- Cardiac: coronaritis, pericarditis, myocarditis, endocarditis, mitral regurgitation, aortic and tricuspidal regurgitation (in the acute phase), aortic dilatation (in the later phase), cardiac failure, shock, arrhythmia, coronary artery involvement (in the sub acute phase)

- Vascular: Raynaud phenomenon, peripheral gangrene

- Joints: arthritis or arthralgia

- Nervous System: irritability, aseptic meningitis, sensor-neural hearing loss, transient unilateral peripheral facial nerve palsy

- Gastrointestinal: diarrhoea, vomiting, abdominal pain, acute surgical abdomen, hepatic enlargement and jaundice, acute acalculous distention of the gallbladder (hydrops)

- Urinary: aseptic pyuria, urethritis, testicular swelling

- Skin: erythema and induration at the site of a previous vaccination with Bacille Calmette-Guérin, Beau lines

- Respiratory: cough, rhinorrea, pulmonary nodules and infiltrates.

Published: 30 September 2015

References

1. Kawasaki T: Acute febrile mucocutaneous syndrome with lymphoid involvement with specific desquamation of the fingers and toes in children. Aerugi 1967, 16(3):178-222. 
2. Kato $H$, Sugimura $T$, Akagi T, Kato H, Sugimura T, Akagi $T$, et al: Long term consequences of Kawasaki disease. A 10- to 21-year follow-up study of 594 patients. Circulation 1996, 94(6):1379-1385.

3. Dajani AS, Taubert KA, Gerber MA, Shulman ST, Ferrieri P, Freed M, et al: Diagnosis and therapy of Kawasaki disease in children. Circulation 1993, 87(5):1776-1780.

4. Newburger JW, Takahashi M, Gerber MA, Gewitz MH, Tani LY, Burns JC, et al: Diagnosis, treatment, and long-term management in Kawasaki disease: a statement for health professionals from the committee on rheumatic fever, endocarditis and Kawasaki disease, council on cardiovascular disease in the young, American Heart Association. Pediatrics 2004, 114(6):1708-1733.

doi:10.1186/1824-7288-41-S2-A47

Cite this article as: Marchesi et al:: Typical Kawasaki disease. Italian Journal of Pediatrics 2015 41(Suppl 2):A47.

\section{Submit your next manuscript to BioMed Central} and take full advantage of:

- Convenient online submission

- Thorough peer review

- No space constraints or color figure charges

- Immediate publication on acceptance

- Inclusion in PubMed, CAS, Scopus and Google Scholar

- Research which is freely available for redistribution

Submit your manuscript at www.biomedcentral.com/submit 